\title{
Expression of a Non-Secreted Form of Juvenile Hormone Esterase in a Baculovirus
}

\author{
Kiyoko TANIAI ${ }^{1 *}$, Carol L. E. ZHOU, Dennis G. LEE, Susumu MAEDA and \\ Bruce D. HAMMOCK ${ }^{2}$
}

Department of Entomology, University of California Davis (Davis, California 95616, USA)

\begin{abstract}
Pericardial cells rapidly cleared recombinant-juvenile hormone esterase (rJHE) expressed within a baculovirus in insects from the hemolymph. To prevent the clearance of rJHE, we used the polymerase chain reaction (PCR) to remove the signal sequence from the JHE gene, thereby converting the enzyme to a non-secreted form (NSJHE). The resulting gene was expressed in a baculovirus (AcNSJHE) using HIGH-FIVE cells and proper cellular enzyme production was monitored. Transcription level of the NSJHE and rJHE were comparable, and purified NSJHE protein from the cytoplasm hydrolyzed JH. However, efficacy of NSJHE production was low. Enzyme-linked immunosorbent assays and enzyme assays demonstrated enzyme production and activity relative to rJHE of $0.5-1.7 \%$ and $<0.1 \%$, respectively. Transmission electron microscopy (TEM) revealed that NSJHE was distributed in the nucleus predominantly and some NSJHE aggregated in clumps within the cytoplasm. These results indicate that NSJHE lacks a specific localization site within cells and that the folding of this enzyme is insufficient. Deglycosylation experiments using purified NSJHE showed that NSJHE was much less glycosylated than rJHE as we expected. Although the NSJHE was less glycosylated, enzyme stability of the NSJHE was equivalent to that of rJHE, indicating that the sugar chains are unimportant in the stability of JHE.
\end{abstract}

Discipline: Biotechnology

Additional key words: recombinant baculovirus, signal peptide, secretion, glycosylation

\section{Introduction}

Juvenile hormone $(\mathrm{JH})$ regulates development and reproduction in insects9. The JH titer decreases dramatically at molting and metamorphosis with the cessation of biosynthesis and the production of hydrolyzing enzymes. Juvenile hormone esterase (JHE) (EC3.1.1.1), one of the principal enzymes involved in $\mathrm{JH}$ metabolism, hydrolyzes the methyl esters in $\mathrm{JH}$ to form inactive $\mathrm{JH}$-acids. Since the reduction in $\mathrm{JH}$ halts feeding ${ }^{6}$, understanding the regulation of JHE may aid in the development of biological control agents. To test the utility of JHE as a biological control agent, we isolated JHE from the tobacco budworm, Heliothis virescens, and inserted it into the AcMNPV genome under the control of the p10 promoter. This recombinant virus expressed $75 \mathrm{mg} / \mathrm{L}$ of active JHE during viral replication in cultured cells ${ }^{6}$. However, pericardial cells rapidly remove the JHE expressed in insect hemolymph ${ }^{8}$, significantly decreasing the efficacy of the recombinant baculovirus as a control agent ${ }^{4}$.

Although the active site and exact function of $\mathrm{JH}$ have not yet been verified, the high lipophilicity of JH suggests that it can penetrate cells. Furthermore, a JH epoxide hydrolase (JHEH) associated with microsomal membranes with catalytic activity on $\mathrm{JH}$ was isolated from the tobacco hornworm, Manduca sexta ${ }^{11}$, and a similar enzyme was purified from Trichoplusia $n i^{10}$. The localization of these JHEHs on microsomes provides additional evidence that JH penetrates cells. We hypothesize that over-expressed JHE within the cytoplasm blocks the activity of JH. To test this hypothesis, we constructed a recombinant baculovirus containing a JHE gene lacking

\footnotetext{
Present address:

${ }^{1}$ Insect Biotechnology and Sericology Department, National Institute of Agrobiological Science (Tsukuba, Ibaraki 305-8634, Japan)

${ }^{2}$ Department of Entomology and Cancer Research Center, University of California Davis (Davis, CA 95616, USA)

*Corresponding author: fax +81-29-838-6100; e-mail taniai@affrc.go.jp

Received 16 August 2004; accepted 22 September 2004.
} 
the signal peptide.

\section{Materials and methods}

\section{Construction of a virus expressing NSJHE}

To remove a signal sequence from JHE gene, PCR method was used to amplify a part (368 bp from 5'-end of mature protein) of JHE coding region and concurrently adding the initiation methionine codon using a plasmid, AcUW2-(B)JHE ${ }^{1}$ as a template. The primer sequences are the following; 5'-CAGTACGAATTCAATTTCGCAA AGATGTGGCAGGAGACAAATTCGCGCAGCGTGC TCGCCCAT-3' (forward) and 5'-GAAGGCTTTGCCAT GGAACATGAATGTTGGCGTATATGCAAGCCTCGC TCATCTCGCTTG-3' (reverse). The PCR product was digested with $N c o$ I, and then ligated to a rest 3'- part NcoI-EcoRI fragment (from 369 to $1709 \mathrm{bp}$ ). The resulting gene encoded full length JHE without the signal sequence. This NSJHE gene was inserted into a pBSK+ plasmid (Stratagene) at the EcoRI site. The nucleotide sequence of the inserted gene was confirmed using the dye terminator cycle sequencing method and a 373A DNA Auto Sequencer (Applied Biosystems). The gene was extracted and was inserted into a transfer vector, pAcUW21, under the p10 promoter. The plasmid DNA (AcUW21-NSJHE) was co-transfected with a linearized viral DNA of Autographa californica nuclear polyhedrosis virus (AcMNPV, C6 strain) onto Sf21 cells using lipofectin (GIBCO). After 7 days, several plaques were purified and subjected to the enzyme assay. One of the virus clones with the highest activity was selected and designated AcNSJHE.

\section{Cells and virus infection}

Sf21 cells in Ex-Cell 401 medium (JRH Biosciences) supplemented with $3 \%$ inactivated fetal calf serum, and HIGH FIVE cells (INVITROGEN) in ExCell 405 medium (JRH Biosciences) were maintained at $26^{\circ} \mathrm{C}$. Sf2 1 cells were used for virus construction and plaque assay. When NSJHE were produced on a large scale, HIGH FIVE cells were infected with 10 plaque forming units per cell and cultured in spinner flasks. An original recombinant virus (AcJHE) producing a secreted form of JHE (rJHE) ${ }^{12}$ was used as a positive control and AcMNPV-C6 was used as a negative control for the enzyme assay, ELISA and Western blots.

\section{Enzyme assay}

JHE activities were assayed using a partition method using a tritiated-JHIII ( $\left.{ }^{3} \mathrm{H}-\mathrm{JHIII}\right)$ as a substrate. Serial dilutions of the samples (cell culture medium, intact cells or purified protein) were made with assay buffer [200
$\mathrm{mM}$ sodium phosphate buffer $(\mathrm{pH} 7.4), 0.01 \%$ BSA, $0.01 \%$ sodium azide] and $100 \mu \mathrm{L}$ was used per reaction. Reactions were initiated by addition of $1 \mu \mathrm{L}$ of (500 nmole) substrate and terminated following incubation at $30^{\circ} \mathrm{C}$ for $15 \mathrm{~min}$ by immediate cooling on ice and addition of $50 \mu \mathrm{L}$ of stop solution ( $50 \%$ methanol, $45 \%$ water, $5 \% \mathrm{NH}_{4} \mathrm{OH}$ ). The JHIII-acid product was extracted by addition of $100 \mu \mathrm{L}$ of trichloroethylene followed by vigorous mixing on a vortex mixer and by centrifugation at $112 \mathrm{~g}$ for $10 \mathrm{~min}$. Fifty $\mu \mathrm{L}$ was removed from the aqueous phase and mixed with $1 \mathrm{~mL}$ of liquid scintillation cocktail for scintillation counting. All values were corrected for non-enzymatic hydrolysis.

\section{ELISA}

Expressed NSJHE and rJHE (protein weight/cell) in HIGH FIVE cells were measured by ELISA using antiJHE polyclonal antibodies. Cells and medium were separated by centrifugation at $700 \mathrm{~g}$ for $10 \mathrm{~min}$. Cell pellets were washed with $100 \mathrm{mM}$ phosphate buffered saline (PBS, pH 7.4) and homogenized in cold PBS containing $2 \mathrm{mM}$ EDTA. Following centrifugation at $10,000 \mathrm{~g}$ for $10 \mathrm{~min}$, the supernatant was diluted with $48 \mathrm{mM}$ sodium carbonate buffer ( $\mathrm{pH}$ 9.6). One hundred $\mu \mathrm{L}$ of each sample was placed per well of the ELISA plates (Nunc, F96 MAXSORP) and stored at $4^{\circ} \mathrm{C}$ for overnight. After all wells were washed twice with $10 \mathrm{mM}$ PBS (pH 7.4) containing $0.05 \%$ Tween 20 (PBST), the remaining surface was blocked with $200 \mu \mathrm{L}$ of $10 \%$ non-fat milk (Bio-Rad) and incubated for $2 \mathrm{~h}$ at room temperature. The primary antibody (anti-JHE) and secondary antibody (peroxidaseconjugated goat anti-rabbit $\mathrm{IgG}$ ) reactions were done using $200 \mu \mathrm{L}$ of each antibody and incubated at $37^{\circ} \mathrm{C}$ for $2 \mathrm{~h}$. After each antibody reaction, the wells were washed three times with PBST. One hundred $\mu \mathrm{L}$ of the substrate (3,3'-5,5-tetramethylbenzidine) was added to each well and incubated at room temperature for $15 \mathrm{~min}$. The reaction was quenched with $50 \mu \mathrm{L}$ of $4 \mathrm{~N} \mathrm{H}_{2} \mathrm{SO}_{4}$ and absorbance was read by microtiter plate reader (Molecular Devices) at $450 \mathrm{~nm}$. Total protein concentration was determined by the Bradford method using a Protein Assay Kit (Bio-Rad).

\section{Western blotting}

The virus-infected cells $\left(10^{6}\right.$ cells $)$ were washed by centrifugation with $100 \mathrm{mM}$ PBS containing $2 \mathrm{mM}$ EDTA. The cell pellets were suspended with three volumes of sample-treatment buffer $(125 \mathrm{mM}$ Tris-HCl, $\mathrm{pH}$ 6.8, $10 \%$ urea, $2.5 \%$ SDS, $5 \% \beta$-mercaptoethanol, $0.005 \%$ bromophenol blue) and were boiled for $5 \mathrm{~min}$. The samples were loaded onto a $10 \%$ polyacrylamide gel and were electrophoresed at $100 \mathrm{~V}$, constant voltage. 
The proteins were then transferred to a nitrocellulose membrane (Bio-Rad) and were probed with an anti-JHE polyclonal antibody. The JHE bands were made visible with a secondary antibody (horse radish peroxidase (HRP)-conjugated with goat anti-rabbit $\mathrm{IgG}$ ), and with ECL Western blotting detection reagents (Amersham). The bands were scanned using a ScanJet 4C (Hewlett Packard), then analyzed using Basic Quantifier software (Genomic Solutions) to determine relative intensity of the bands.

\section{6. mRNA blotting}

Poly(A)-RNAs were purified from cells using a MicroPrep mRNA Purification Kit (Pharmacia), and 200 ng of mRNA was electrophoresed on a $1.2 \%$ agarose containing $6.6 \%$ formaldehyde, and then transferred onto a positively charged nylon membrane (Boehringer Mannheim). For dot blotting, one microgram of mRNA was spotted onto a nylon membrane (Boehringer Mannheim). The DIG system (Boehringer Mannheim) was used to detect JHE-mRNA. Briefly, the membranes were incubated in a hybridization solution (50\% formamide, $5 \times \mathrm{SSC}, 7 \% \mathrm{SDS}, 50 \mathrm{mM}$ sodium-phosphate, $\mathrm{pH} 7.0$, $0.1 \% \mathrm{~N}$-lauroylsarcosine, $2 \%$ blocking reagent) at $48^{\circ} \mathrm{C}$ for $2 \mathrm{~h}$. DIG-labeled JHE-probe was prepared using PCR with a plasmid $3 \mathrm{hv} 16 \mathrm{~B}^{5}$ as a template. One hundred ng of the probe was added to the solution that was then incubated at $50^{\circ} \mathrm{C}$ overnight. The membranes were rinsed twice with $2 \times$ SSC, $0.1 \%$ SDS, and washed twice with $0.5 \times \mathrm{SSC}, 0.1 \% \mathrm{SDS}$ at $68^{\circ} \mathrm{C}$. After the reaction with alkaline phosphatase-conjugated anti-DIG antibody and following the luminescence reaction with substrate, the chemiluminescent signal was detected by exposure of the membrane to X-ray film. The relative intensity of the dots were analyzed as same as bands of Western blots.

\section{Transmission electron microscopy (TEM) and immunogold labeling}

HIGH FIVE cells were infected with wild-type (AcMNPV) or recombinant (AcJHE and AcNSJHE) viruses or were mock-infected with no virus. After $60 \mathrm{~h}$, cells were resuspended in warm $\left(37^{\circ} \mathrm{C}\right) 0.1 \mathrm{M} \mathrm{Na}_{2} \mathrm{~K}-$ phosphate buffer, $\mathrm{pH} 7.2$, containing $0.75 \%$ SeaKem Gold agarose (FMC BioProducts, Rockland, ME). Agar blocks containing cells were immediately sliced and fixed in $2 \%$ paraformaldehyde, $0.1 \%$ glutaraldehyde in the same buffer, dehydrated in a standard ethanol series to $70 \%$ ethanol, and infiltrated and embedded in LR White resin. Blocks were heat polymerized at $60^{\circ} \mathrm{C}$, then sectioned with diamond knives (Diatome) on an RMC ultramicrotome at $100 \mathrm{~nm}$. The sections were mounted on nickel grids and treated with a 1:500 dilution of pri- mary antibody followed by a 1:75 dilution of secondary antibody (15 nm gold-conjugated goat anti-rabbit), the sections were stained with aqueous uranyl acetate and lead citrate, then viewed on a Zeiss EM10 transmission electron microscope operating at $80 \mathrm{kv}$. All reagents were obtained from Ted Pella, Redding, CA, unless indicated otherwise.

\section{Affinity column purification}

HIGH FIVE cells were collected at $72 \mathrm{~h}$ post inoculation (p. i.) with AcJHE or with AcNSJHE, and homogenized in ice cold-purification buffer [200 mM sodium phosphate buffer ( $\mathrm{pH} 7.4$ ), 5\% sucrose, $2 \mathrm{mM}$ EDTA, $0.02 \%$ sodium azide] using POLYTRON (Brinkmann Instruments). The homogenate was centrifuged at $100,000 \mathrm{~g}$ for $20 \mathrm{~min}$ and the supernatant was mixed with an affinity resin $\left(\mathrm{CF}_{3}-\mathrm{CO}-\mathrm{CH}_{2} \mathrm{~S}\left(\mathrm{CH}_{2}\right)_{4} \text {-S-Sepharose }\right)^{7}$. After overnight binding at $4^{\circ} \mathrm{C}$, the resin was washed with purification buffer, then washed with the buffer containing $0.1 \%$ of octyl beta-D glucopyranoside, and was then incubated with the buffer in the presence of $1 \mathrm{mM}$ of an inhibitor OTFP [3-(n-octylthio)-1,1,1-trifluoro-2-propanone $]^{5}$ to elute JHE from the resin. Eluted JHE was dialyzed for 4 days against purification buffer in the dialysis bag (m.w. 12,000-14,000 cut-off, Spectrapor) to remove OTFP from JHE. The dialyzed solution was concentrated and desalted using Centricon 30 (Amicon).

\section{Deglycosylation of NSJHE}

To remove the N-linked glycan chain, N-Glycosidase $\mathrm{F}$ (Boehringer Mannhaim) was used at 0.3 units per $100 \mathrm{ng}$ of each affinity purified-JHE in $250 \mathrm{mM}$ sodium phosphate buffer ( $\mathrm{pH}$ 8.6) containing $0.14 \%$ SDS and $0.42 \%$ octanoyl-N-methyl-glucamide (Boehringer Mannhaim). After overnight incubation at $37^{\circ} \mathrm{C}$, the enzyme was inactivated by addition of sample treatment buffer for SDS-PAGE and heating at $90^{\circ} \mathrm{C}$ for $10 \mathrm{~min}$, then analyzed by SDS-PAGE followed by Western blotting. The procedures for SDS-PAGE and Western blotting are as described above.

\section{Enzyme stability}

Affinity purified NSJHE and rJHE were stored at room temperature for 28 days. A portion of each solution was subjected to the enzyme assay in triplicate periodically during storage.

\section{Results and discussion}

\section{Expression efficiency of NSJHE}

Enzyme activity of NSJHE was detected in cells (Table 1); about $34.4 \%$ and $58.2 \%$ activity was found in 
Table 1. Expression of NSJHE and rJHE in HIGH-FIVE cells

\begin{tabular}{|c|c|c|c|c|}
\hline \multirow[b]{2}{*}{ (h p. i.) } & \multicolumn{2}{|c|}{ NSJHE } & \multicolumn{2}{|c|}{ rJHE } \\
\hline & $\begin{array}{l}\text { Activity/total protein } \\
(\mathrm{pmol} / \mathrm{min} / \mathrm{mg})\end{array}$ & $\begin{array}{l}\text { JHE weight } \\
(\mu \mathrm{g} / \mathrm{mL})\end{array}$ & $\begin{array}{l}\text { Activity/total protein } \\
\quad(\mathrm{nmol} / \mathrm{min} / \mathrm{mg})\end{array}$ & $\begin{array}{l}\text { JHE weight } \\
(\mu \mathrm{g} / \mathrm{mL})\end{array}$ \\
\hline \multicolumn{5}{|l|}{ Cells } \\
\hline 24 & $14.1 \pm 4.2$ & $0.15 \pm 0.00$ & $1.8 \pm 1.8$ & $0.00 \pm 0.00$ \\
\hline 48 & $169.3 \pm 48.3$ & $1.31 \pm 0.33$ & $43.4 \pm 17.9$ & $5.56 \pm 0.39$ \\
\hline 72 & $252.3 \pm 10.4$ & $0.46 \pm 0.06$ & $53.9 \pm 9.5$ & $5.66 \pm 0.39$ \\
\hline 96 & $162.9 \pm 0.9$ & $0.24 \pm 0.03$ & $24.2 \pm 2.1$ & $4.94 \pm 0.82$ \\
\hline \multicolumn{5}{|l|}{ Medium } \\
\hline 24 & $4.6 \pm 7.4$ & $0.01 \pm 0.00$ & $50.7 \pm 7.15$ & $0.68 \pm 0.04$ \\
\hline 48 & $322.8 \pm 20.6$ & $0.01 \pm 0.00$ & $809.7 \pm 122.5$ & $71.60 \pm 5.38$ \\
\hline 72 & $181.5 \pm 18.5$ & $0.01 \pm 0.00$ & $1,174.0 \pm 113.0$ & $91.66 \pm 1.99$ \\
\hline 96 & $2.0 \pm 2.7$ & $0.01 \pm 0.00$ & $287.6 \pm 24.6$ & $80.44 \pm 5.85$ \\
\hline
\end{tabular}

JHE activities were determined by the assay using tritiated-JH III as a substrate. JHE weight was measured by ELISA using anti-JHE polyclonal antibodies. The values for these two assays were corrected using values for control AcMNPV. Total proteins were measured by Bradford protein assay using bovine serum albumin as a standard. Means \pm SD values are given for tests done in triplicate.

\section{A. Western blot}
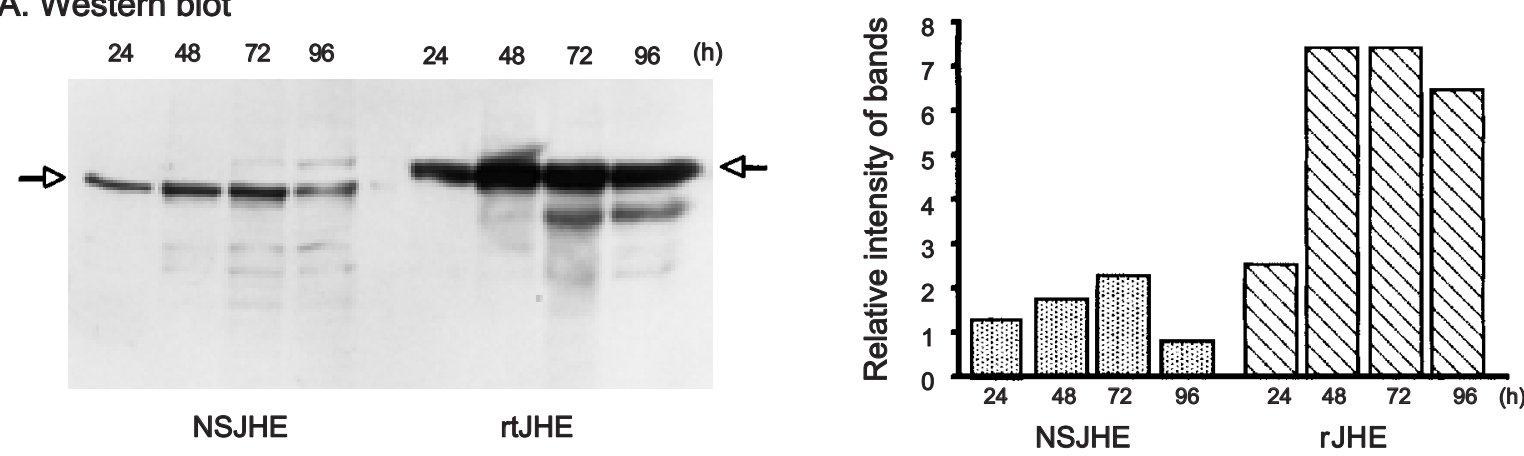

B. Northern- and Dot-blots
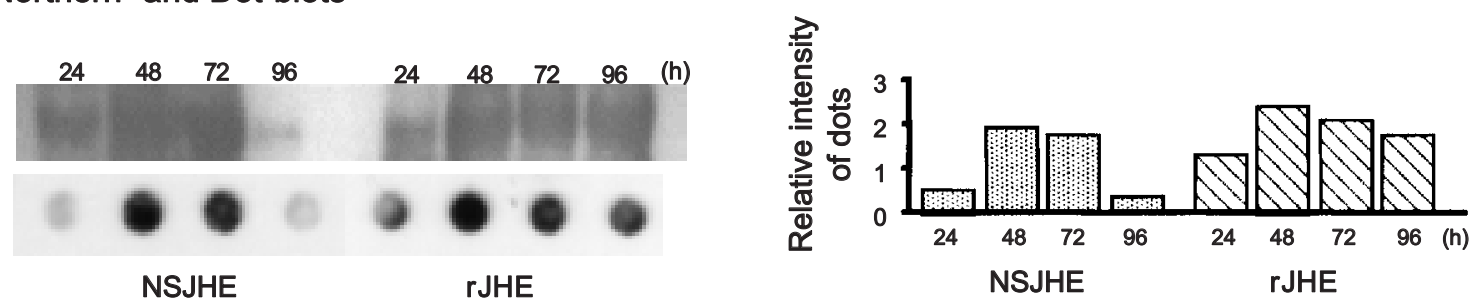

Fig. 1. Time course of NSJHE and rJHE expression

A: Western blots of JHE expressed from cells 24, 48, 72, and $96 \mathrm{~h}$ post-inoculation (p. i.) are shown at the left. JHE bands are indicated by arrows. Band intensity is indicated relative to the checked (NSJHE) and striped (rJHE) bars on the right. No JHE protein signal was detected with the two controls; AcMNPV and mock-infected cells (data not shown).

B: The upper picture shows the results of Northern blot, and dot-blots are on the lower left. The data are NSJHE and rJHE mRNA for a time series $24,48,72$, and $96 \mathrm{~h} \mathrm{p}$. i. The intensity of the dots is relative to the checked (NSJHE) or striped (rJHE) bars on the right. No JHE-mRNA signal was detected with the controls; AcMNPV or mock-infected cells (data not shown). 
cells at peak times (48 and $72 \mathrm{~h}$, respectively) of expression. NSJHE protein was little detected in the medium by ELISA at any time p. i. In contrast, $96 \%$ of rJHE activity and $94 \%$ of rJHE-protein were detected in the medium at a peak time ( $72 \mathrm{~h} \mathrm{p}$. i.) of expression. However, both the enzyme assay and the ELISA showed extremely low production of NSJHE compared with those of rJHE. Total activity of NSJHE at $72 \mathrm{~h} \mathrm{p}$. i. (433.8 $\mathrm{pmol} / \mathrm{min} / \mathrm{mL}$ ) was only $0.035 \%$ of that of $\mathrm{rJHE}$ $(1,227.9 \mathrm{nmol} / \mathrm{min} / \mathrm{mL})$. This activity was lower than the activity predicted for the JHE protein. Even though the amount of NSJHE protein in cells at $72 \mathrm{~h}$ p. i. $(0.46 \mu \mathrm{g} /$ $\mathrm{mL}$ ) was about $8 \%$ that of rJHE, the activity was only $0.5 \%$. Western blot analysis also indicated that the quantity of NSJHE protein was considerably higher than $0.4 \%$ that of rJHE (Fig. 1A). These results indicate that the NSJHE did not have enough activity corresponding to the expressed protein. Western blot analysis shows that NSJHE accumulated during the first 3 days p. i. A few faint bands were observed at a size smaller than $61 \mathrm{kDa}$.

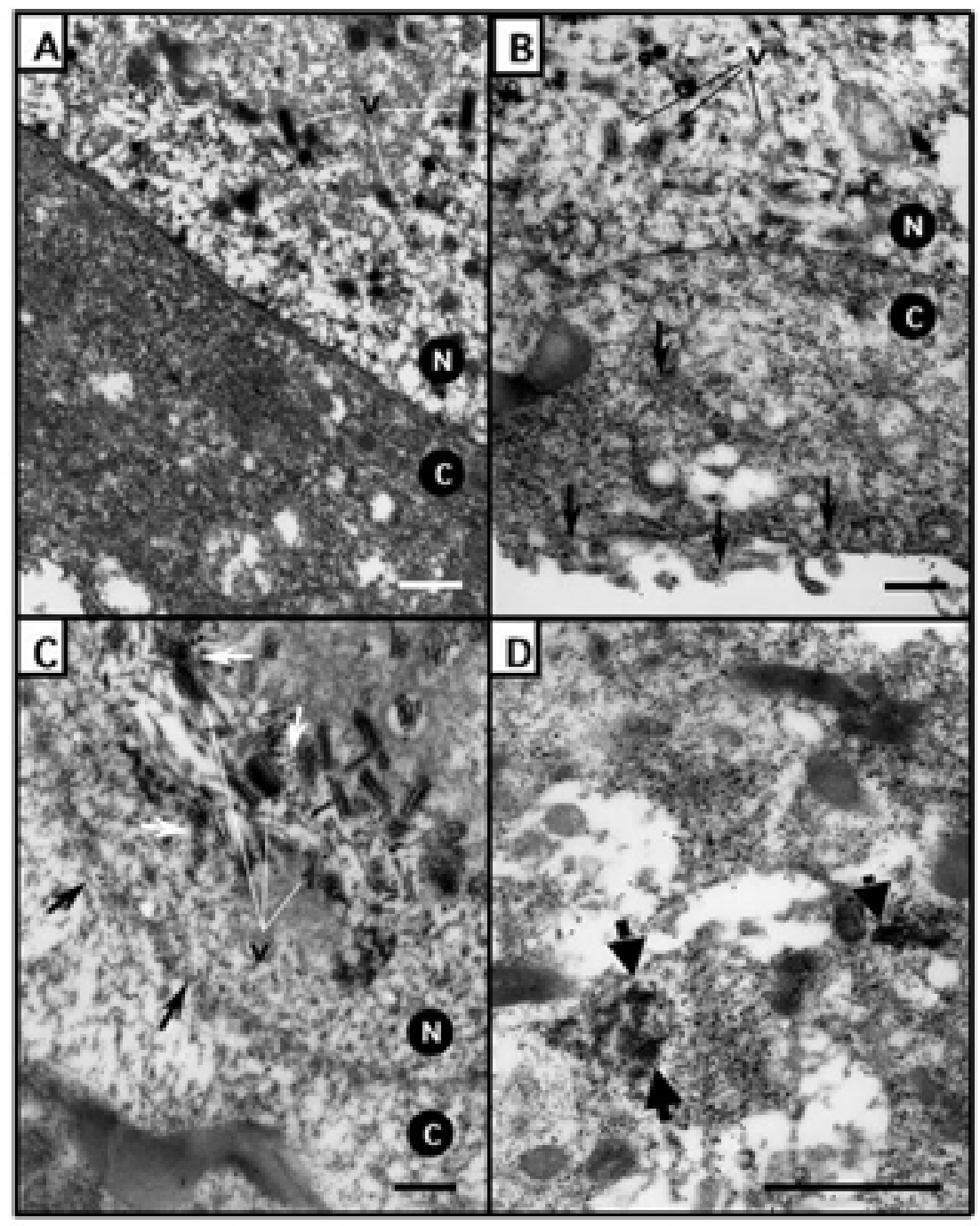

Fig. 2. TEM of HIGH FIVE cells harvested 60 h p. i. with (A) AcMNPV (wild-type virus), (B) AcJHE, and (C, D) AcNSJHE

A: Cells infected with AcMNPV were not stained with gold-conjugated anti-JHE antibody.

B: Arrows indicate gold stained rJHE in the cytoplasm. Some gold labeling was detected along the plasma membrane and immediately outside the cells (black arrows).

C: Some NSJHE in the nucleus was associated with virions (white arrows) or the nuclear membrane (black arrows).

D: Clusters of NSJHE with gold particles (arrows) within the cytoplasm.

$\mathrm{v}$ : virion; (C): cytoplasm; $\mathbb{( N )}$ : nucleus. Scale bars $=500 \mathrm{~nm}$. 
From the results, it appears that NSJHE was not degraded rapidly in cells.

In order to characterize mRNA stability of NSJHE, accumulation of its mRNA was compared with that of rJHE. As shown in Fig. 1B, the intensity of mRNA signals of NSJHE in both Northern blot- and dot blot-analyses was similar to that of rJHE at 48 and $72 \mathrm{~h} \mathrm{p}$. i. The signals for NSJHE were weaker than those of rJHE at 24 and $96 \mathrm{~h}$ p. i., which indicates that mRNA of NSJHE was a little less stable than that of rJHE. However, the extremely low expression of NSJHE can not be explained by instability of the mRNA, since the transcription of NSJHE was strong enough to express a similar quantity of rJHE protein at the peak time (48 to $72 \mathrm{~h} \mathrm{p}$. i.).

\section{Immunological detection of rJHE and NSJHE}

TEM observation revealed a predominant immunogold staining of NSJHE within the nuclei (Fig. 2C). In contrast, rJHE was detected mainly in the cytoplasm and around plasma membrane (Fig. 2B). NSJHE in nuclei was frequently observed in association with virions and with the nuclear membrane, and was found in the cytoplasm in apparent aggregates (Fig. 2D). Control cells exhibited little immunogold staining (Fig. 2A). From this observation, the synthesized NSJHE might associate with virion structural protein(s) in cytoplasm, then be transported to the nucleus with the virus protein(s). NSJHE in nuclei may lose activity, perhaps due to conformational changes resulting from binding to virion proteins. In addition, probably NSJHE was inadequately folded in the cytoplasm. NSJHE was observed to occur as aggregates in the cytoplasm (Fig. 2D); these aggregates may consist of misfolded NSJHE. Sufficient folding of JHE probably requires support of the ER luminal factor(s). Possible factors involved might include an oxidized glutathione or protein disulfide isomerase.

\section{Affinity purification of NSJHE}

NSJHE was purified from cells, and rJHE was purified from both cells and medium with one step of affinity column chromatography. The yields were $37.5,48.1$ and $96.6 \%$, respectively, based on the enzyme activities (Table 2). NSJHE from cells showed nine bands ranging in size from 50 to $65 \mathrm{kDa}$ on SDS-PAGE gel (Fig. 3A), and three of the bands reacted with anti-JHE antibody (Fig. 3B). The two major bands were $61 \mathrm{kDa}$ and $50 \mathrm{kDa}$, and one faint band was $65 \mathrm{kDa}$. On the other hand, a single band of $65 \mathrm{kDa}$ was observed with rJHE from the medium on both SDS-PAGE and Western blot. From the results, the purity of NSJHE was judged to be about $30 \%$. Although the purity of NSJHE was low, specific activity (0.52 $\mathrm{mmol} / \mathrm{min} / \mathrm{mg})$ was relatively high, which was about $42 \%$ that of rJHE (12.2 $\mathrm{mmol} / \mathrm{min} / \mathrm{mg}$ ) (Table 2 ).

Table 2. Purification of the recombinant JHEs from HIGH FIVE cells by affinity chromatography*

\begin{tabular}{|c|c|c|c|c|c|c|c|}
\hline & $\begin{array}{l}\text { Total activity } \\
(\mu \mathrm{mol} / \mathrm{min} / \mathrm{L})\end{array}$ & $\begin{array}{l}\text { Total protein } \\
\text { (mg) }\end{array}$ & $\begin{array}{l}\text { Specific activity } \\
(\mu \mathrm{mol} / \mathrm{min} / \mathrm{mg})\end{array}$ & $\begin{array}{l}\text { Purification } \\
\text { (-fold) }\end{array}$ & $\begin{array}{l}\text { Yield protein } \\
(\%)\end{array}$ & $\begin{array}{l}\text { Yield activity } \\
(\%)\end{array}$ & $\begin{array}{c}\text { Purity }^{* *} \\
(\%)\end{array}$ \\
\hline \multicolumn{8}{|c|}{ NSJHE (cells) } \\
\hline Cell lysate & 0.08 & 338 & 0.00024 & 1 & 100 & 100 & \\
\hline Affinity & 0.03 & 0.14 & 0.52 & 2166.7 & 0.017 & 37.5 & $<30$ \\
\hline \multicolumn{8}{|l|}{ wtJHE (cells) } \\
\hline Cell lysate & 18.7 & 390 & 0.048 & 1 & 100 & 100 & \\
\hline Affinity & 9.0 & 0.8 & 11.3 & 235.4 & 0.2 & 48.1 & $>95$ \\
\hline \multicolumn{8}{|c|}{ wtJHE (medium) } \\
\hline Medium & 75.8 & 250 & 0.3 & 1 & 100 & 100 & \\
\hline Affinity & 73.2 & 6 & 12.2 & 40.7 & 2.4 & 96.6 & $>95$ \\
\hline
\end{tabular}

* One liter $\left(5 \times 10^{8}\right)$ of HIGH FIVE cells were infected with AcNSJHE or AcJHE, respectively, then harvested $72 \mathrm{~h} \mathrm{p}$. i.

** Purity estimated are based on densitometry scan of SDS-PAGE gel following staining with Coomassie Brilliant Blue. 
A

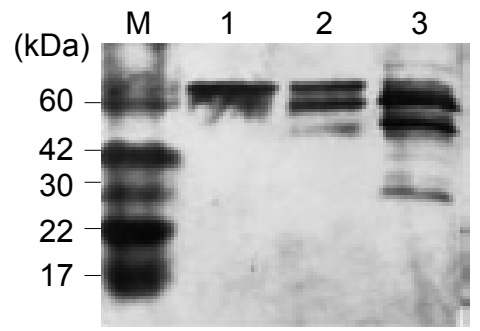

B

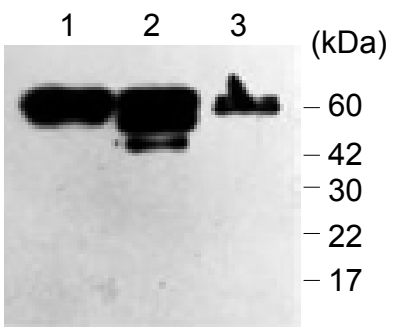

Fig. 3. Purified recombinant JHE

A: Silver staining of affinity-purified JHE in a 10\% SDS-PAGE gel. Lanes: M, molecular size markers; 1, rJHE from medium; 2, rJHE from cells; 3, NSJHE from cells.

B: Western blot of the SDS-PAGE gel.

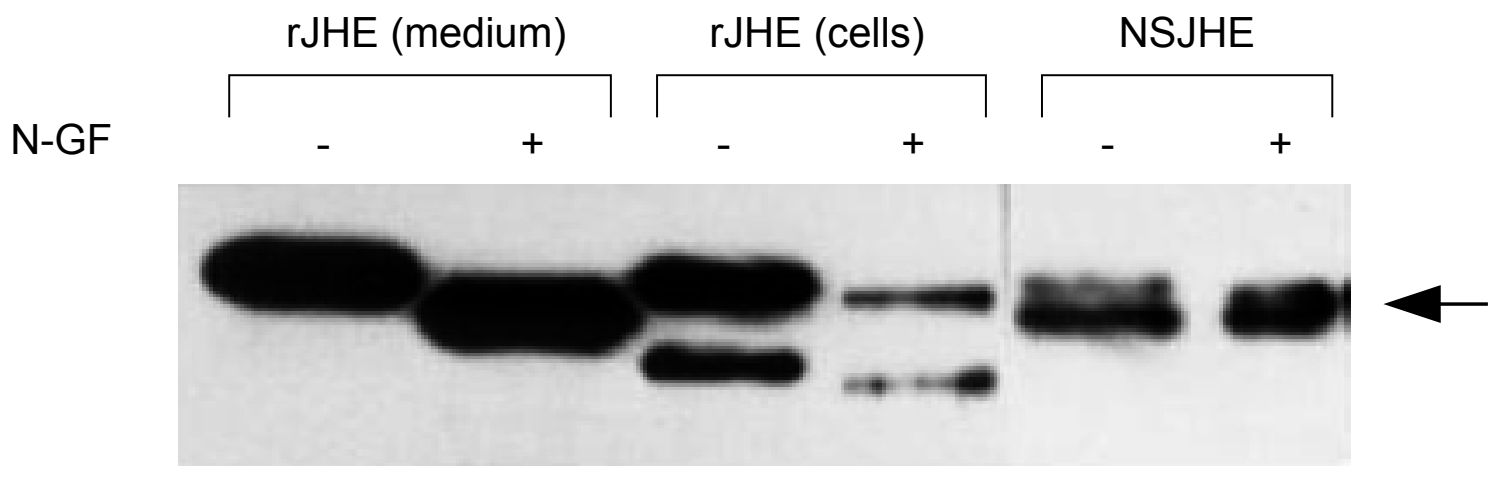

Fig. 4. Deglycosylation of rJHE and NSJHE

Affinity-purified rJHE and NSJHE digested with (+) or without $(-) \mathrm{N}$-glycosidase F were separated in a $10 \%$ SDS-PAGE gel to determine changes in mobility. rJHE from medium and from cells shifted to a distinctly lower molecular weight, whereas the major NSJHE band (arrow) was unchanged after deglycosylation.

\section{Deglycosylation and stability of NSJHE}

By Western blot analysis the molecular size of the NSJHE $(61 \mathrm{kDa})$ was determined to be approximately $4 \mathrm{kDa}$ smaller than that of rJHE (Fig. 1A). Since this is virtually identical to the size of JHE $(61.012 \mathrm{kDa})$ predicted from the nucleotide sequence, NSJHE seems not to be modified with glycan chains. To further characterize the carbohydrate on both the recombinant JHEs, endoglycosidase digestion was performed on purified rJHE from the medium and from cells, and NSJHE from cells. Each protein was digested with N-glycosidase then monitored by SDS-PAGE followed by Western blotting. All rJHE bands had shifted to lower molecular positions (Fig. 4). However, no mobility change was found for the major band (ca. $61 \mathrm{kDa}$ ) of NSJHE. Another faint 65 $\mathrm{kDa}$ band had shifted to a slightly smaller size.

In order to compare stability of JHE with and without glycosylation, affinity-purified NSJHE and rJHE stored at room temperature were periodically subjected to JHE assay. As shown in Fig. 5, activities for both JHEs were unchanged during the experimental period. From

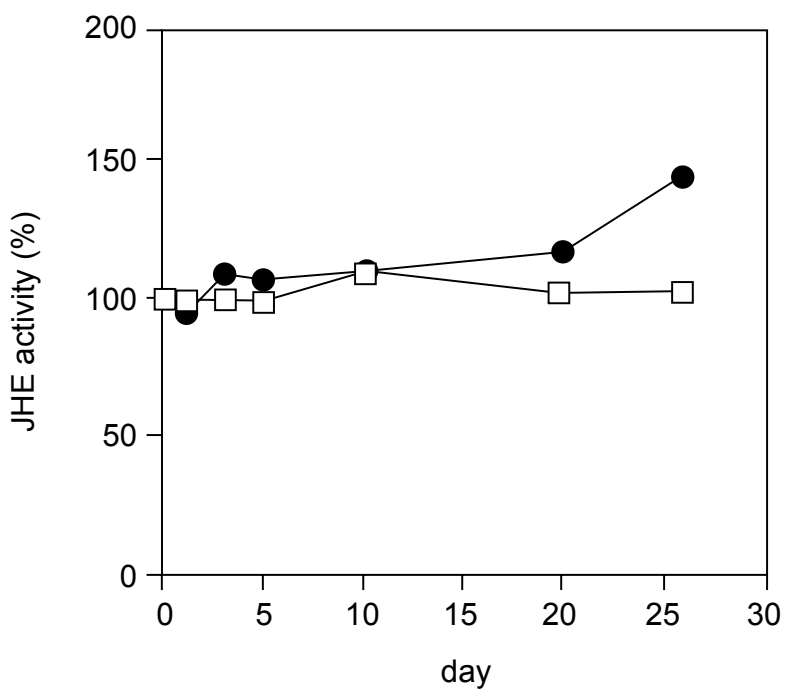

Fig. 5. Enzyme stability of rJHE and NSJHE

Affinity-purified rJHE and NSJHE were stored at room temperature for 28 days under sterile conditions. At various times during this period, portions of the enzyme solutions were subjected to the assay. The activities are shown as percentages of the original activity.

: NSJHE, $\square$ : rJHE purified from the medium. 
the results, we concluded that saccharide chains are not important for stability of this enzyme. However, whatever role the glycan chains may have in JHE folding is unknown.

\section{Conclusion}

Expression of JHE lacking the signal sequence resulted in low production of functional JHE. Two possible reasons for the reduced activity were suggested, which were insufficient localization and misfolding. Sf21 cells infected with AcNSJHE tend to be degraded earlier than the cells infected with AcJHE or AcMNPV, and insects ( $H$. viresens larvae) injected with AcNSJHE showed unusually collapsed dead bodies in comparison to the insects injected with AcJHE or AcMNPV (data not shown). These effects were probably due to the abnormal accumulation of NSJHE in cells, but not due to overexpressed JHE activity. As several attempts to express modified JHE in baculovirus systems have proved successful in improving virus insecticidal activities: for example, SG-JHE, which was modified at catalytic sites ${ }^{2}$, and KK-JHE, which was mutated at putative lysosomal targeting sites $^{3}$, further modification of the JHE gene by addition of ER retention- or membrane anchor-signals so as to synthesize JHE via the ER lumen may improve expression efficacy of NSJHE.

\section{Acknowledgements}

This work was supported in part by the USDA (2003-35302-13499), and NIEHS R37 ES02710, P42 ES04699 and P30 ES05707.

\section{References}

1. Bonning, B. C. et al. (1992) Further development of a recombinant baculovirus insecticide expressing the enzyme juvenile hormone esterase from Heliothis virescens. Insect Biochem. Mol. Biol., 22, 453-458.

2. Bonning, B. C. et al. (1995) Development of a recombinant baculovirus expressing a modified juvenile hormone esterase with potential for insect control. Arch. Insect Biochem. Physiol., 30, 177-194.

3. Bonning, B. C. et al. (1997) Disruption of lysosomal targeting is associated with insecticidal potency of juvenile hormone esterase. Proc. Natl. Acad. Sci. USA, 94, 60076012.

4. Eldridge, R. et al. (1992) Insecticidal properties of genetically engineered baculoviruses expressing an insect juvenile hormone esterase gene. Appl. Environ. Microbiol., 58, 1583-1591.

5. Hammock, B. D. et al. (1984) Substituted thiotrifluoropropanones as potent selective inhibitors of juvenile hormone esterase. Pestic. Biochem. Physiol., 22, 209-223.

6. Hammock, B. D. et al. (1990) Expression and effects of the juvenile hormone esterase in a baculovirus vector. Nature, 344, 458-461.

7. Hanzlik, T. N. \& Hammock, B. D. (1987) Characterization of affinity-purified juvenile hormone esterase from Trichoplusia ni. J. Biol. Chem., 262, 13584-13591.

8. Ichinose, R. et al. (1992) Pharmacokinetic studies of the recombinant juvenile hormone esterase in Manduca sexta. Pestic. Biochem. Physiol., 42, 13-23.

9. Riddiford, L. M. (1996) Molecular aspects of juvenile hormone action in insect metamorphosis. In Metamorphosis, eds., Gilbert, L. I., Tata, J. R. \& Atkinson, B. G., Academic Press Inc., New York, 223-251.

10. Roe, R. M. et al. (1996) Mechanism of action and cloning of epoxide hydrolase from the cabbage looper, Trichoplusia ni. Arch. Insect Biochem. Physiol., 32, 527-535.

11. Touhara, K. \& Prestwich, G. D. (1993) Juvenile hormone epoxide hydrolase. J. Biol. Chem., 268, 19604-19609.

12. Ward, V. K. et al. (1992) Analysis of the catalytic mechanism of juvenile hormone esterase by site-directed mutagenesis. Int. J. Biochem., 24, 1933-1941. 